\title{
SHEAR BOND STRENGTH OF ORTHODONTIC BRACKETS TO ENAMEL UNDER DIFFERENT SURFACE TREATMENT CONDITIONS
}

\author{
Matheus Melo PITHON ${ }^{1}$, Márlio Vinícius de OLIVEIRA², Antonio Carlos de Oliveira RUELLAS ${ }^{3}$, \\ Ana Maria BOLOGNESE ${ }^{4}$, Fábio Lourenço ROMANO
}

\begin{abstract}
1- DDS, Specialist in Orthodontics, School of Dentistry, Federal University of Alfenas, Alfenas, MG, Brazil; Student of the Master's Degree Program in Orthodontics, School of Dentistry, Federal University of Rio de Janeiro, Rio de Janeiro, RJ, Brazil.

2- DDS, Specialist in Orthodontics, School of Dentistry, Federal University of Alfenas, Alfenas, MG, Brazil.

3- DDS, MSc, PhD, Adjunct Professor of Orthodontics, School of Dentistry, Federal University of Rio de Janeiro, Rio de Janeiro, RJ, Brazil: Professor of the Specialization Course in Orthodontics, School of Dentistry, Federal University of Rio de Janeiro, Rio de Janeiro, RJ, Brazil. 4- DDS, MSc, PhD, Chair Professor of Orthodontics, School of Dentistry, Federal University of Rio de Janeiro, Rio de Janeiro, RJ, Brazil. 5- DDS, MSc, Student of the PhD Program in Orthodontics, Dental School of Piracicaba, State University of Campinas, Piracicaba SP, Brazil; Professor of the Specialization Course in Orthodontics, School of Dentistry, Federal University of Alfenas, Alfenas, MG, Brazil.
\end{abstract}

Corresponding address: Matheus Melo Pithon - Rua México, 78, Vitória da Conquista, Bahia, Brazil - 45020-390 - Phone/Fax: 55773421 2750 - e-mail: matheuspithon@bol.com.br

Received: October 02, 2006 - Modification: December 14, 2006 - Accepted: April 02, 2007

\begin{abstract}
T 1 he purpose of the present study was to evaluate the shear bond strength to enamel and the adhesive remnant index (ARI) of both metallic and polycarbonate brackets bonded under different conditions. Ninety bovine permanent mandibular incisors were embedded in acrylic resin using PVC rings as molds and assigned to 6 groups $(\mathrm{n}=15)$. In Groups 1 (control) and 3, metallic and polycarbonate orthodontic brackets were, respectively, bonded to the enamel surfaces using Transbond XT composite according to the manufacturer's recommendations. In Groups 2 and 4, both types of brackets were bonded to enamel with Transbond XT composite, but XT primer was replaced by the OrthoPrimer agent. In Groups 5 and 6, the polycarbonate bracket bases were sandblasted with $50-\mu \mathrm{m}$ aluminum-oxide particle stream and bonded to the enamel surfaces prepared under the same conditions described in Groups 3 and 4, respectively. After bonding, the specimens were stored in distilled water at $37^{\circ} \mathrm{C}$ for 24 hours and then submitted to shear bond strength test at a crosshead speed of $0.5 \mathrm{~mm} / \mathrm{min}$. The results (MPa) showed no statistically significant difference between Groups 4 and $6(p>0.05)$. Likewise, no statistically significant differences ( $p>0.05)$ were found among Groups 1, 2, and 5, although their results were significantly lower than those of Groups 4 and 6 ( $p<0.05$ ). Group 3 had statistically significant lower bond strength than Groups 2, 4, and 6, but no statistically significant differences were found on comparison to Groups 1 and 5. A larger number of fractures at the bracket/composite interface were evidenced by the ARI scores. OrthoPrimer bonding agent yielded higher bond strength in the groups using either conventional or sandblasted polycarbonate brackets, which was not observed in the groups using metallic brackets.
\end{abstract}

Uniterms: Shear strength; Dental bonding; Orthodontic brackets.

\section{INTRODUCTION}

The great technological advance occurred in the last years has brought a number of benefits to Dentistry and particularly to Orthodontics. Research-based findings have constantly led to the development of new materials and techniques that are aimed at simplifying the clinical procedures.

Several studies involving different dental areas have been carried out since the development of the enamel acid conditioning technique by Buonocore ${ }^{4}$ (1955). In Orthodontics, in particular, Newman ${ }^{17}$ (1965) was the first author to test the bonding of plastic attachments (polycarbonate brackets) to the buccal surfaces of the teeth and to divulge such a technique.

Several authors ${ }^{1,10,11}$ have used different materials and adhesive techniques with the objective of improving the bonding durability and developing more suitable orthodontic attachments. Different types of cements, epoxy and acrylic resins as well as different types of orthodontic brackets are currently available.

In 1965 , Newman ${ }^{17}$ reported that plastic brackets were not resistant enough, being easily fractured or distorted. Other authors ${ }^{8,18,19,29,30}$ have studied adhesive materials and different types of brackets commonly used in Orthodontics in order to increase their adhesiveness to the enamel surface. 
One of the methods of increasing bracket bonding involves application of a primer to their surface ${ }^{21}$. Other method involves aluminum-oxide sandblasting of the bracket base for increasing the bond strength ${ }^{20,26,27}$.

The purpose of this study was to assess the bond strength to enamel of metallic brackets, conventional polycarbonate brackets and polycarbonate brackets with aluminum-oxide sandblasted bases, bonded with Transbond XT composite and using two different bonding agents: XT Primer and OrthoPrimer.

\section{MATERIALAND METHODS}

Ninety bovine mandibular incisors were selected, adequately cleansed and stored in $10 \%$ formaldehyde solution at approximately $6{ }^{\circ} \mathrm{C}$.

A acrylic resin (JET; Clássico, São Paulo, SP, Brazil) was used for embedding the teeth in PVC rigid rings (Tigre, Joinville, SC, Brazil) in such a way that only their crowns were left exposed. The buccal surfaces of these crowns were positioned perpendicular to the shearing die's base by using a glass square placed at $90^{\circ}$ angle in order to enable the proper conduction of the mechanical test. After gypsum setting, all sets were stored in distilled water under refrigeration.

Before bonding the brackets, the buccal surfaces of all teeth were submitted to rubber cup (Viking KG Sorensen, Barueri, SP, Brazil) prophylaxis using an extra-fine pumice (S.S. White, Juiz de Fora, MG, Brazil) and water slurry for 15 seconds. Next, the specimens were thoroughly washed with air/water spray for 15 seconds and air-dried for the same length of time. At every five prophylaxis, the rubber cup was replaced in order to keep the standardization. After prophylaxis, the enamel surfaces were etched with $37 \%$ phosphoric acid (Dentsply, Petrópolis, RJ, Brazil) during 15 seconds, washed and dried for the same length of time. The acid-etched specimens were randomly assigned to 6 groups $(\mathrm{n}=15)$, as follows:

Group 1: application of XT Primer; application of Transbond XT composite to the metallic bracket (Morelli, Sorocaba, SP, Brazil) base; positioning; and excess removal.

Group 2: application of Morelli OrthoPrimer; application of Transbond XT composite to the metallic bracket base; positioning; and excess removal.

Group 3: application of XT Primer; application of Transbond XT composite to the polycarbonate bracket (Composite, Morelli, Sorocaba, Brazil) base; positioning; and excess removal.

Group 4: application of Morelli OrthoPrimer; application of Transbond XT composite to the polycarbonate bracket base; positioning; and excess removal.

Group 5: sandblasting of the polycarbonate bracket base with $50-\mu \mathrm{m}$ aluminum oxide particle stream at a distance of 5 cm for 10 seconds; application of XT Primer and Transbond $\mathrm{XT}$ composite to the sandblasted polycarbonate bracket base; positioning, and excess removal.

Group 6: Sandblasting of the polycarbonate bracket base

with $50-\mu \mathrm{m}$ aluminum oxide particle stream at a distance of 5 cm for 10 seconds; application of Morelli OrthoPrimer and Transbond XT composite to the sandblasted polycarbonate bracket base; positioning, and excess removal.

The main components of the tested adhesive systems are: XT Primer: TEG-DMA, and Bis-GMA; OrthoPrimer: Bis-GMA, TEG-DMA, HEMA 2, DMPT, camphorquinone and stabilizers.

The bonding process of all brackets involved light curing using a XL 1500 halogen light-curing unit (3M/ESPE, St. Paul, MN, USA) at a distance of $1 \mathrm{~mm}$ from the bracket base for 40 seconds, that is, 10 seconds for mesial, distal, incisal and gingival surfaces. Light intensity $\left(550 \mathrm{~m} \mathrm{~W} / \mathrm{cm}^{2}\right)$ was checked at each light-curing cycle with a radiometer (Demetron, Danbury, CT, USA).

A surface base area of $14.02 \mathrm{~mm}^{2}$ was obtained for the groups treated with either the metallic or the polycarbonate brackets. After completion of the bonding procedures, the specimens were stored in distilled water at $37^{\circ} \mathrm{C}$ for 24 hours. The shear bond strength test was performed by using an Instron machine (Instron Corporation, Canton, MA, USA) at a crosshead speed of $0.5 \mathrm{~mm} / \mathrm{min}$ using a chisel-shaped nib. The shear bond strength means obtained in kgf were converted to $\mathrm{N}$ and then divided by the bracket base area to obtain values in MPa. The debonded buccal surface of each specimen was evaluated with a stereoscopic magnifying glass (Carl Zeiss, Goettingen, Germany) at 8X magnification and the adhesive remnant index (ARI) was quantified according to the criteria established by Artun and Bergland ${ }^{2}$ (1984), that is, $0=$ no adhesive left on tooth, $1=$ less than half of the adhesive left on tooth, $2=$ more than half of the adhesive left on tooth, and $3=$ all the adhesive left on tooth.

Shear bond strength means were analyzed statistically by one-way ANOVA and Tukey's test for multiple comparisons. Kruskal-Wallis test was used for assessing the ARI scores. Significance level was set at 5\%.

\section{RESULTS}

Shear bond strength means and standard deviations of all groups are given on Table 1 .

Groups 4 and 6 had higher shear bond strength means

TABLE 1- Shear bond strength means (in MPa) for all groups, presented from the highest to the lowest

\section{Groups Means (Standard deviations)}

6

4

2

1

5

3

Equal letters $=$ no statistically significant difference
24.32 (3.0)a
$22.00(5.2) a$
$15.25(3.0) b$
13.45 (3.5)bc
13.22 (4.3)bc
$10.86(3.4) \mathrm{c}$ 
than those of the other groups $(\mathrm{p}<0.05)$, although no statistically significant differences were found between them $(\mathrm{p}>0.05)$. Additionally, no statistically significant differences $(p>0.05)$ were found between Groups 1, 2, and 5. On the other hand, Group 3 had statistically significant lower shear bond strength than Groups 2, 4, and 6, but did not differ significantly, from Groups 1 and 5.

No statistically significant differences $(p>0.05)$ were found between the groups according to the ARI evaluation (Table 2).

Group 6 showed the highest shear bond strength means, which was supported by the types of fracture observed in the polycarbonate brackets after debonding.

\section{DISCUSSION}

In Orthodontics, the acid etching technique introduced by Buonocore 4 (1955) fostered the development of orthodontic brackets and clinical attachment of them to the enamel surface directly using adhesive restorative composites, which both eliminates the use of orthodontic bands and simplifies the clinical steps. Bonding of brackets to enamel surface using composites is currently a wellaccepted and well-established procedure in Orthodontics and the efficacy of this technique has been widely documented ${ }^{3,11}$

However, in order to satisfy both the orthodontist and the patient, the dental industry has been incessantly developing esthetic orthodontic attachments as well as bonding materials capable of withstanding the orthodontic and masticatory forces.

Bracket debonding resulting from factors, such as failure in the bonding technique, low retentiveness of certain bracket bases, masticatory forces ${ }^{7}$ and reduced size of the bracket base for esthetic reasons ${ }^{9}$ are common shortcomings in clinical orthodontics, and might delay treatment completion and increase the costs relative to the maintenance of fixed orthodontic appliances. With the objective of minimizing these problems, several solutions have been proposed such as aluminum-oxide sandblasting ${ }^{7,9,12,15,20,25-27}$ and primer application ${ }^{8,18}$.

The present study assessed the shear bond strength of metallic brackets, conventional polycarbonate brackets and polycarbonate brackets with sandblasted bases, all bonded

TABLE 2- Mean values for Adhesive Remnant Index (ARI) and statistical comparison

$\begin{array}{ll}\text { Group 1 } & 2.0 \mathrm{a} \\ \text { Group 2 } & 2.4 \mathrm{a} \\ \text { Group 3 } & 2.0 \mathrm{a} \\ \text { Group 4 } & 1.8 \mathrm{a} \\ \text { Group 5 } & 1.1 \mathrm{a} \\ \text { Group 6 } & 1.8 \mathrm{a}\end{array}$

Equal letters $=$ no statistically significant difference using two different bonding agents for preparation of the enamel surfaces, namely, XT Primer and OrthoPrimer.

Comparing the bond strength of the groups in which OrthoPrimer was used, it was observed an increased adhesiveness regarding the metallic brackets. Such increase is in accordance with the findings of previous studies ${ }^{3,21,24}$, which investigated the bond strength and effectiveness of a primer for bracket attachment.

The best results for OrthoPrimer were obtained when this agent was applied for bonding polycarbonate brackets. These brackets do not present good shear bond strength when composites other than those based on methyl methacrylate are used, thus resulting in failure at the bracket/ composite interface, as observed in Group 3. In Group 4, on the other hand, the use of OrthoPrimer (based on methyl methacrylate) increased considerably the adhesion of the polycarbonate brackets to the composite without interfering with the bond strength of either composite to enamel or composite to metallic bracket (Groups 1 and 2).

The results were found to be statistically different in the groups whose brackets were sandblasted with aluminumoxide particle stream, which is consistent with the findings of other studies ${ }^{13-15,23,28}$. On the other hand, our results disagree with those reported by Hanson, et al. ${ }^{5}$ (1983), Julien ${ }^{6}$ (1994) and Newman ${ }^{16}$ (1973), who did not find any statistically significant differences. Although the bond strength at bracket/composite interface was not significantly increased by bracket base sandblasting, this treatment did not affect negatively the bonding quality at all.

In the groups where either conventional or sandblasted polycarbonate brackets were bonded to enamel surfaces with OrthoPrimer (Groups 4 and 6, respectively), no statistically significant differences were found, which demonstrates that the bond strength was not increased by sandblasting.

In Group 6 (sandblasted polycarbonate brackets), more specifically, the fractures observed on the tie-wings of the brackets after shear bond strength testing were likely due to the high adhesive scores of these specimens and the structural weakness of the material as well. Deformation on sandblasted polycarbonate bracket bases was also found by Bishara, et al. ${ }^{3}$ (1975), who evaluated the performance of two adhesive systems for bonding this type of bracket.

It should be emphasized, however, that all types of surface treatments accomplished in the present study proved to be clinically valuable because all treatment protocols resulted in bond strength means of at least 6 to $8 \mathrm{MPa}$, proposed by Reynolds and Frauhofer ${ }^{22}$ (1976) as being necessary for withstanding the masticatory forces.

ARI assessment revealed no statistically significant differences among the groups, although Groups 4, 5, and 6 showed lower mean ARI scores than those of Groups 1, 2, and 3. This probably was due to the changes in the polycarbonate bracket bases, which promoted an increased retention of the material to the bracket. However, most failures occurred at the bracket/composite interface, as demonstrated by the presence of adhesive remnants on the enamel surface. 


\section{CONCLUSIONS}

1. Metallic and polycarbonate brackets showed clinically acceptable shear bond strengths; 2. Replacement of XT Primer by OrthoPrimer in the groups using metallic brackets did not influence the bond strength; 3. Application of the OrthoPrimer bonding agent increased the bond strength of the sandblasted polycarbonate bracket bases to enamel; 4 . OrthoPrimer yielded higher bond strength of the sandblasted polycarbonate bracket bases to enamel, which made debonding more difficult and caused fractures on the tiewings of the brackets.

\section{REFERENCES}

1- Aguirre MJ, King GJ, Waldron JM. Assessment of bracket placement and bond strength when comparing direct bonding to indirect bonding techniques. Am J Orthod. 1982;82:269-76.

2- Artun J, Bergland S. Clinical trials with crystal growth conditioning as an alternative to acid-etch enamel pretreatment. Am J Orthod. $1984 ; 85: 333-40$

3- Bishara SE, Khowassah MA, Oesterle LJ. Effect of humidity and temperature changes on orthodontic direct-bonding adhesive systems. J Dent Res. 1975;54:751-8.

4- Buonocore MG. A simple method of increasing the adhesion of acrylic filling materials to enamel surfaces. J Dent Res. 1955;34:849-53.

5- Hanson GH, Gibbon WM, Shimizu H. Bonding bases coated with porous metal powder: a comparison with foil mesh. Am J Orthod. $1983 ; 83: 1-4$.

6- Julien MPR. Estudo comparative "in vitro", da capacidade adesiva entre bráquetes com micro e macro retenções colados em pré-molares humanos, em diversos períodos de tempo [dissertação]. São Paulo (SP): Faculdade de Odontologia, Universidade de São Paulo; 1994.

7- Katona TR, Long RW. Effect of loading mode on bond strength of orthodontic brackets bonded with 2 systems. Am J Orthod Dentofacial Orthop. 2006;129:60-4

8- Lopez JI. Retentive shear strengths of various bonding attachment bases. Am J Orthod. 1980;77:669-78.

9- Maccoll GA, Rassouw PE, Titley KC, Yasmin C. The relationship between bond strength and orthodontic bracket base surface area with conventional and microetched foil-mesh bases. Am J Orthod Dentofacial Orthop. 1998;113:276-81

10- Mcalarney ME, Brenn P. A modified direct technique versus conventional direct placement of brackets: in vitro bond strength comparison. Am J Orthod. 1993;104:575-83.

11- Miguel JAM, Almeida MAA, Chevitarese O. Clinical comparison between a glass ionomer cement and a composite for direct bonding of orthodontic brackets. Am J Orthod Dentofacial Orthop. 1995;107:4847 .

12 - Millett D, Mccabe JF, Gordon PH. The role of sandblasting on the retention of metallic brackets applied with glass ionomer cement. Br J Orthod. 1993;20:117-22.
13 - Mondelli ALM. Estudo comparativo da resistência adesiva da interface resina/bráquete, sob esforços de cisalhamento, empregando três resinas compostas e três tipos de tratamentos na base do bráquete [tese]. Bauru (SP): Faculdade de Odontologia de Bauru, Universidade de São Paulo; 2004.

14 - Newman GV, Newman RA, Sun BI, Ha JLJ, Ozsoylu SA. Adhesion promoters, their effect on the bond strength of metal brackets. Am J Orthod Dentofacial Orthop. 1995;108:237-41.

15- Newman GV, Sun BC, Ozsoylu SA, Newman RA. Update on bonding brackets: an in vitro survey. J Clin Orthod. 1994;28:396-402.

16- Newman GV. Current status of bonding attachments. J Clin Orthod. $1973 ; 7: 425-49$

17- Newman GV. Epoxy adhesives for orthodontics attachments: progress report. Am J Orthod. 1965;51:901-12.

18 - Özcan M, Vallittu PK, Peltomäki T, Huysmans MC, Kalk W. Bonding polycarbonate brackets to ceramic: effects of substrate treatment on bond strength. Am J Orthod Dentofacial Orthop. 2004;126:220-7.

19- Öztoprak MO, Isik F, Sayýnsu K, Arun T, Aydemir B. Effect of blood and saliva contamination on shear bond strength of brackets bonded with 4 adhesives. Am J Orthod Dentofacial Orthop. 2007;131:238-42.

20 - Penido SMMO, Martins JCR, Santos Pinto A, Sakima MT. Avaliação da resistência ao cisalhamento de bráquetes reciclados e novos recolados. Rev Dent Press Ortodon Ortopedi Facial. 1998;3:45-52.

21 - Pulido LG, Powers JM. Bond strength of orthodontic direct-bonding cement-plastic bracket systems in vitro. Am J Orthod. 1983;83:124-30.

22 - Reynolds IR, Fraunhofer JA. Direct bonding in orthodontics: a comparison off attachments. Br J Orthod. 1976;4:65-9.

23- Sant'Anna EF, Monnerat ME, Chevitarese Stuani MBS. Bonding brackets to porcelain: in vitro study. Braz Dent J. 2002;13:191-6.

24- Scribante A, Cacciafesta V, Sfondrini MF. Effect of various adhesive systems on the shear bond strength of fiber-reinforced composite. Am J Orthod Dentofacial Orthop. 2006;130:224-7.

25 - Sonis AL. Air abrasion of failed bonded metal brackets: a study of shear bond strength and surface characteristics as determined by scanning electron microscopy. Am J Orthod Dentofacial Orthop. 1996;110:968 .

26- Tavares SW, Consani S, Nouer DF, Magnani MBBA, Pereira JS Neto. Evaluation in vitro of the shear bond strenght of aluminum oxide recycled brackets. Braz J Oral Sci. 2003;2:378-81.

27 - Tavares SW. Estudo in vitro da resistência ao cisalhamento de bráquetes reciclados e novos [dissertação]. Piracicaba (SP): Faculdade de Odontologia de Piracicaba, Universidade Estadual de Campinas; 2002.

28 - Velasquez NZ. Estudo comparativo das uniões bráquete/resina/dente; bráquete/resina/cobre - alumínio; bráquete/resina/níquel - cromo; bráquete/resina/porcelana, mediante testes de cisalhamento, utilizando as resinas Enforce e Concise [dissertação]. Bauru (SP): Faculdade de Odontologia de Bauru, Universidade de São Paulo; 1998.

29- Vicente A, Bravo LA, Romero M, Ortíz AJ, Canteras M. Effects of 3 adhesion promoters on the shear bond strength of orthodontic brackets: an in-vitro study. Am J Orthod Dentofacial Orthop. 2006;129:390-5.

30 - Yi GK, Dunn WJ, Taloumis LJ. Shear bond strength comparison between direct and indirect bonded orthodontic brackets. Am J Orthod Dentofacial Orthop. 2003;124:577-81. 